\title{
Natural killer cells: role in local tumor growth and metastasis
}

This article was published in the following Dove Press journal:

Biologics:Targets and Therapy

4 April 2012

Number of times this article has been viewed

Inge Langers ${ }^{1, *}$

Virginie M Renoux ${ }^{1, *}$

Marc Thiry ${ }^{2}$

Philippe Delvenne'

Nathalie Jacobs'

'Laboratory of Experimental Pathology, GIGA-I3/GIGA-Cancer, University of Liège, ${ }^{2}$ Cellular and

Tissular Biology, GIGA-Neurosciences,

University of Liège, Liège, Belgium

*These authors contributed equally to this work
Correspondence: Nathalie Jacobs Laboratory of Experimental Pathology, GIGA-I3, University of Liège, B23/4, Sart Tilman, 4000 Liège, Belgium

$\mathrm{Tel}+3243662420$

Fax +3243669583

Email n.jacobs@ulg.ac.be
Abstract: Historically, the name of natural killer (NK) cells came from their natural ability to kill tumor cells in vitro. From the 1970s to date, accumulating data highlighted the importance of NK cells in host immune response against cancer and in therapy-induced antitumor response. The recognition and the lysis of tumor cells by NK cells are regulated by a complex balance of inhibitory and activating signals. This review summarizes NK cell mechanisms to kill cancer cells, their role in host immune responses against tumor growth or metastasis, and their implications in antitumor immunotherapies via cytokines, antibodies, or in combination with other therapies. The regulatory role of NK cells in autoimmunity is also discussed.

Keywords: natural killer, tumor, cytotoxicity, natural cytotoxicity receptor

\section{Introduction to natural killer cells in antitumor immune response}

Natural killer (NK) cells were discovered in humans and mice in 1975 due to specific functional criteria corresponding to their ability to lyse certain tumor cells in the absence of prior stimulation. ${ }^{1}$ They possess a morphology of large granular lymphocytes (Figure 1A) and their receptor genes involved in the recognition of pathogens remain in germinal configuration unlike $\mathrm{T}$ and $\mathrm{B}$ cells. ${ }^{2}$ Thus, they differ from the $\mathrm{T}$ and $\mathrm{B}$ lymphocytes by the permanent presence of a significant fraction of educated and primed cells. ${ }^{3}$ The formulation of the hypothesis of "missing self" by Klas Kärre, based on the fact that NK cells are able to detect and lyse cells with a deficient expression of major histocompatibility complex class I (MHC-I) molecules, allowed a better understanding of the function and the role of NK cells in the immune response. ${ }^{4}$ In the 1990s, several studies highlighted the presence of inhibiting and activating receptors expressed by NK cells $s^{5}$ that led to the identification of a new recognition model called "induced-self." This new model complements the hypothesis of "missing-self" by explaining why NK cells kill tumor cells expressing MHC-I molecules or save autologous cells with absent MHC-I expression (Figure 2). Indeed, NK cell triggering is the result of a complex balance between inhibitory and activating signals and require not only a deficient MHC-I expression on target cells but also the expression of inducible ligands of activating NK cell receptors. ${ }^{7}$ Consequently, these cells have the ability to recognize and destroy a wide range of abnormal cells (including tumor cells, virusinfected cells, cells bound by an antibody, allogeneic cells), as well as stressed cells, without damaging the healthy and normal "self" cells. ${ }^{8}$ Therefore, NK cells have several important effector functions such as the initiation and amplification of the 


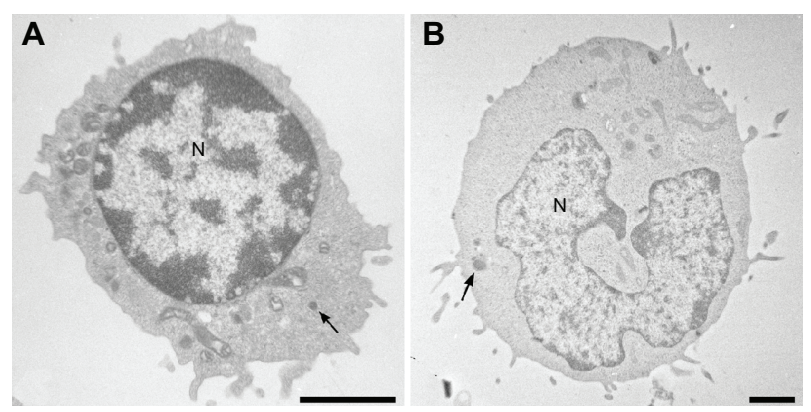

Figure I Electron micrographics of natural killer (A) and NK-92 (B) cells showing large lymphocyte-containing granules (arrows).

Note: Scale bar, $2 \mu \mathrm{m}$.

Abbreviation: $\mathrm{N}$, nucleus.

inflammatory response, the production of chemokines and cytokines, and the lysis of sensitive target cells., ${ }^{9}, 10$

NK cells represent $5 \%$ to $20 \%$ of peripheral blood mononuclear cells, usually defined as CD16+ CD56+ CD3 - cells and are also found in many tissues such as
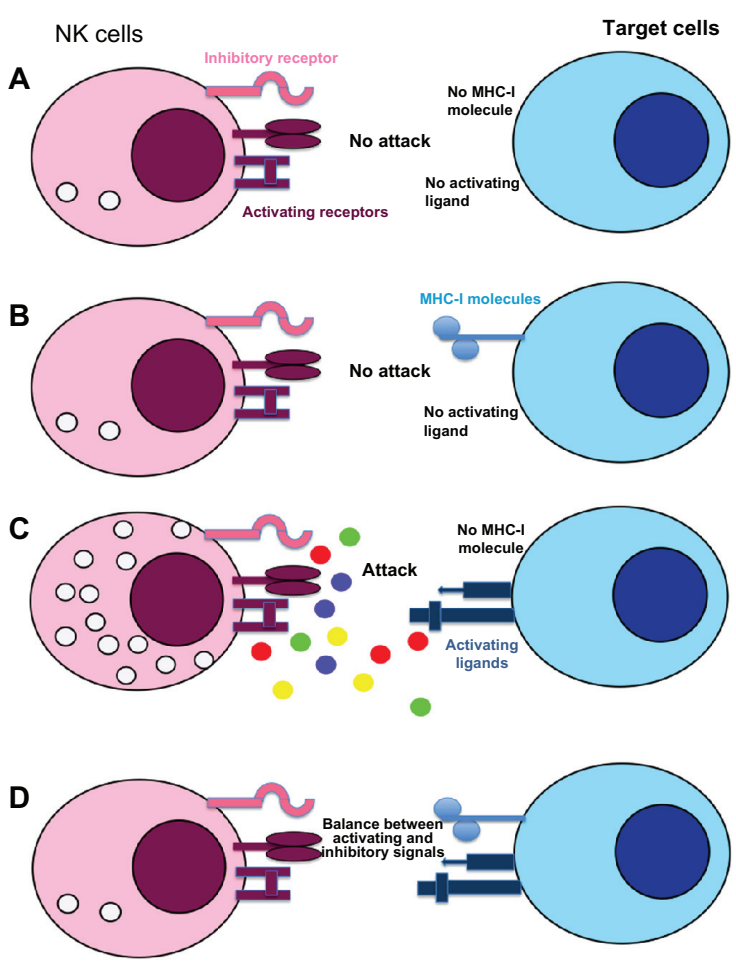

Figure 2 Recognition mechanisms of target cells by NK cells: "missing and induced self" theory. NK cell response is not initiated if neither ligands for NKactivating receptors nor MHC-I are expressed on target cells (A). If inhibitory receptors interact with $\mathrm{MHC}-\mathrm{I}$ molecules without ligands for activating receptors no cytotoxicity is observed (B), whereas engagement of these receptors in absence of MHC-I molecule induced a strong NK cell response (C). In most cases, NK cell response depends on a balance between inhibitory and activating receptor signaling (D). Normal cells are protected against NK cell cytotoxicity because they usually express MHC-I molecules and no or low level of activating receptor ligands.

Notes: In contrast, cell transformation could induce a down-modulation of MHC-I molecules and/or an overexpression of ligands for activating receptors resulting in NK cell recognition and tumor cell lysis.

Abbreviations: MHC-I: major histocompatibility complex class I; NK, natural killer. liver, peritoneal cavity, placenta, or the uterine mucosa. ${ }^{11-14}$ Human NK cells can be divided into two subpopulations according to the density of CD16 and CD56 expression on their surface (Figure 3). The majority of NK cells in blood (90\%-95\%) or at inflammation sites have a moderate expression of CD56 (CD56 $\left.{ }^{\mathrm{dim}}\right)$ and a strong expression of CD16 (Figure 3). These cells possess a high cytotoxic potential. ${ }^{15}$ The CD56 ${ }^{\text {bright }}$ subpopulation predominates in lymph nodes, expresses no or low levels of CD16, displays little cytotoxicity, and mainly produces cytokines upon activation (Figure 3). ${ }^{16} \mathrm{CD} 56$ is not expressed on mouse NK cells, but recently Hayakawa and Smyth ${ }^{17}$ categorized these cells depending on their CD27 expression. Mouse CD27 bright NK cells share several characteristics with human CD56 $6^{\text {bight }}$ NK cells. Accordingly, they predominate in lymph nodes and produce large amounts of cytokines. Recently, the discovery of a new NK marker, NKp46, allowed to define human and mice NK cells because, in contrast to others markers (CD16 and CD56 for humans or DX5 or NK1.1 for mice), NKp46 is exclusively expressed by all NK cells in both species. ${ }^{18}$

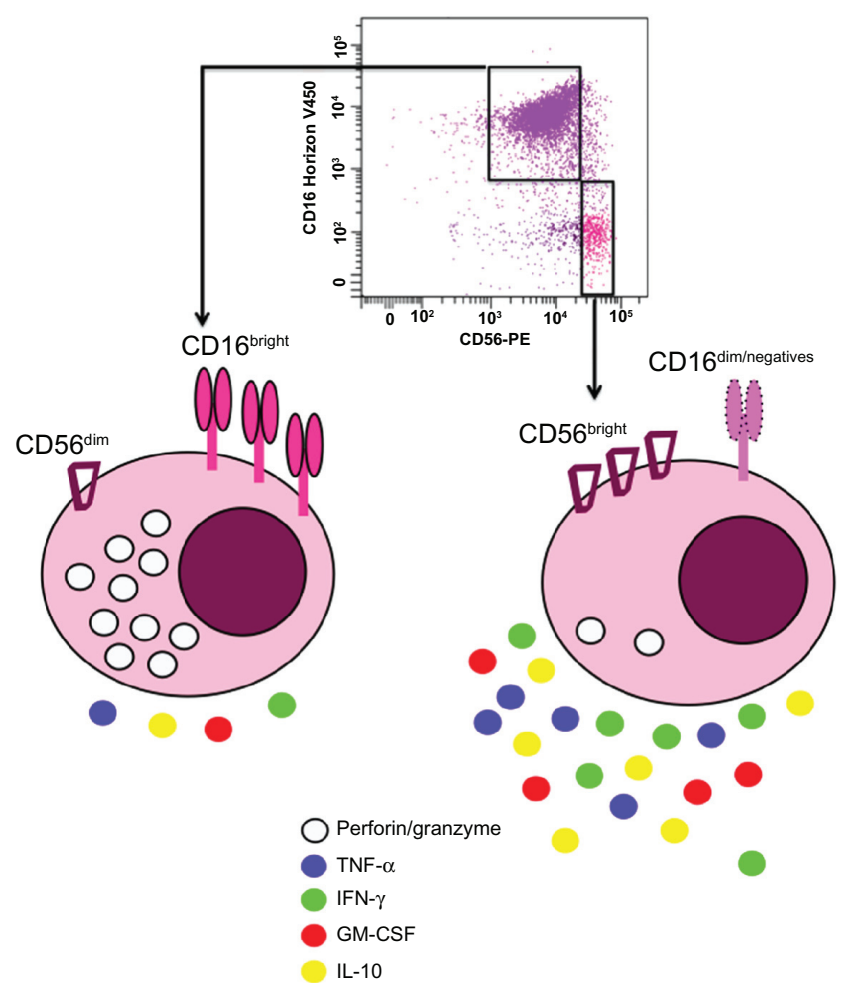

Figure 3 Human natural killer cell subsets based on CD56 and CD 16 expressions: Around $90 \%$ of natural killer cells isolated from the blood display dim level of CD56 and high density of CDI6 (CD56 $6^{\text {dim }}$ CDI $6^{\text {bright }}$ ).

Notes: These cells are more cytotoxic via perforin and granzyme secretion ${ }^{15}$ than natural killer cells showing bright expression of CD56 and no or low expression of CDI6 (CD56 bright CD 16-1low). These latter cells produce more cytokines. ${ }^{16}$

Abbreviations: GM-CSF, granulocyte-macrophage colony-stimulating factor; IFN- $\gamma$, interferon $\gamma$; IL-I0, interleukin I0; TNF- $\alpha$, tumor necrosis factor $\alpha$. 


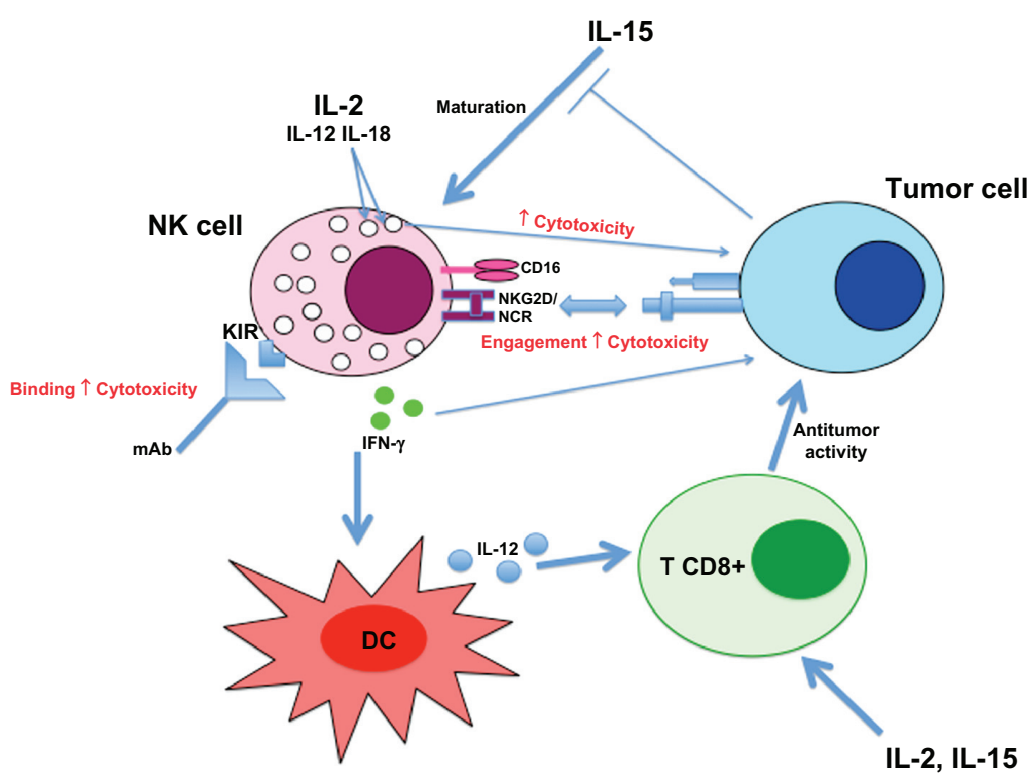

Figure 4 Overview of NK cell responses against tumor cell.

Abbreviations: NK, natural killer; DC, dendritic cell; IFN- $\gamma$, interferon $\gamma$; IL, interleukin; KIR, killer-cell immunoglobulin-like receptor; mAb, monoclonal antibody; NCR, natural cytotoxicity receptor; TNF- $\alpha$, tumor necrosis factor $\alpha$.

Several NK cell lines have been established from lymphoma or peripheral blood mononuclear cells such as NK-92 ${ }^{19}$ (Figure 1B) or $\mathrm{NKG},{ }^{20}$ respectively.

From their discovery, NK cells were described as white blood cells able to lyse tumor cells such as K562, a tumor cell line generated from a patient with chronic leukemia. ${ }^{21}$ Shortly thereafter, NK cells were shown to eliminate circulating tumor cells in mice, ${ }^{22}$ but also to kill spontaneously cells deficient for MHC-I. ${ }^{4}$ The generation of mice genetically deficient for NK cells or depleted of these cells by antibodies, highlighted that NK cells have a role in immunosurveillance of cancer and the ability to prevent the tumor growth. ${ }^{23-25}$ Indeed, the transplantation of lymphoma cells in mice conduct to a more aggressive tumor growth in NK cell deficient mice compared to wild type mice. ${ }^{26}$

\section{Review of the activation and mechanism of action of NK cells}

Unlike T and B lymphocytes, NK cells will not rearrange their genes encoding for receptor antigen recognition, but they have the ability to recognize target cells directly through inhibitory or activating receptors expressed on the cell surface. The balance between stimulatory and inhibitory signals will determine the activation status of NK cells since lysis of the target cell will only happen when the activating signals outweigh the inhibitory signals. The first checkpoint is the expression of MHC-I molecules. ${ }^{4,27}$ In fact, downregulation of MHC-I is observed during tumor transformation ${ }^{28}$ or viral infection ${ }^{29}$ and prevents the binding of inhibitory receptors of NK cells to the target cell. Simultaneously, ligands for activating receptor of NK cells must be expressed on the target cell to trigger NK cell cytotoxicity. These ligands are absent or expressed in low amounts on normal cells, although they are highly expressed on potentially harmful cells as a consequence of cellular stress, viral infection, or tumor transformation.

Different mechanisms are known to be involved in the destruction of tumor cells by NK cells:

- Perforin/granzyme-mediated cytotoxicity: The release of cytotoxic granules composed of perforin and granzymes $^{30}$ is the fastest and also the most powerful way to lyse tumor cells. By creating a synapse with the target cell, NK cells will drop, at this junction, perforin and granzyme molecules inducing the lysis of the target cell. ${ }^{31}$ Mice deficient for perforin are less efficient (about 10 to 100 times) to suppress syngeneic MHC-I deficient tumor cells, suggesting that this molecule is required for NK cell cytotoxicity. ${ }^{32}$ Moreover, many studies have shown that perforin is important for the immunosurveillance of several spontaneous malignancies ${ }^{33}$ whereas the role of granzymes is less characterized..$^{34}$

- Death receptor mediated apoptosis: The death of the target cell, induced by apoptosis via tumor necrosis factor (TNF) family ligands, Fas ligand (CD178), TNF, and TRAIL (tumor-necrosis factor-related apoptosis-inducing ligand), ${ }^{35}$ is an alternative to the release of granules. 
This second mechanism, which is slower (several hours) and often less efficient than the previous one, requires the presence of the TNF family ligand expression on the surface of NK cells. These ligands will bind to a receptor Fas on the surface of the target cell. The effectiveness of this pathway is controlled by various factors such as expression of the receptor for FasL or TRAIL by the cancer cells or intracellular mechanisms protecting against apoptosis. For example, a murine subset of NK cells in liver expressing TRAIL has been shown to kill cancer cells and clear tumors from the liver. ${ }^{36}$

- Interferon- $\gamma$ effector functions: After activation, NK cells secrete various cytokines such as interferon $\gamma$ (IFN- $\gamma$ ), TNF- $\alpha$, granulocyte-macrophage colony-stimulating factor (GM-CSF), interleukin (IL)-10, or IL-13 and their antitumor activities can be mediated by IFN- $\gamma \cdot{ }^{37}$ Indeed, IFN- $\gamma$ produced by NK cells contributes to eliminate tumor metastases and sarcoma induced by methylcholanthrene in a murine model..$^{38}$ This cytokine inhibits proliferation of tumor cells in vitro and indirectly the tumor growth in vivo by inducing the antiangiogenic factors, IP-10. ${ }^{39}$ IFN- $\gamma$ has been also described to enhance NK cell cytotoxicity by overexpressing adhesion molecules or by increasing the sensitivity of tumor cells to cytotoxicity mediated by granule release or death receptor engagement. ${ }^{40}$ TRAIL expression on murine liver NK cells is dependent on IFN- $\gamma$ expression and contributes to the natural antimetastatic role of these NK cells. ${ }^{36}$ IFN- $\gamma$ induced TRAIL expression is also implicated in the IL-12 mediated anti-metastatic effect. ${ }^{24}$

Additionally, IFN- $\gamma$ plays a role in the stimulation of dendritic cells (DC). In combination with CD40 engagement, IFN- $\gamma$ induces IL-1 2 production by DCs. ${ }^{41}$ In this way, NK cells contribute indirectly to tumor control by helping the initiation and maintenance of an efficient $\mathrm{T}$ cell-mediated antitumor response via a crosstalk with DC.42,43

\section{Overview on the NK cells receptor types, history, and discovery NK cell inhibitory receptors}

As previously mentioned, it was originally proposed by Kärre et $\mathrm{al}^{4}$ that NK cells discriminate target cells from normal cells by the level of MHC-I expression on the cell surface. NK cells preferentially lyse cells expressing few or no MHC-I. ${ }^{44}$ The sensitivity of cells with low MHC-I expression to NK cell lysis may be prevented by the re-expression of these molecules ${ }^{45,46}$ Three families of inhibitory receptors recognizing MHC-I molecules were described (Table 1): KIR (killer cell immunoglobulin-like receptor, humans), ${ }^{47,48}$ Ly49 (mice), ${ }^{49,50}$ and CD94/NKG2A (human and mice) ${ }^{51-53}$ receptor family.

Immunoreceptor tyrosine-based inhibitory motif(ITIM), present in all cytoplasmic domains of NK cell inhibitory receptors, is able to recruit intracellular tyrosine phosphatases SHP-1 and SHP-2, which inhibit cytotoxicity and cytokine production. ${ }^{54}$

KIR receptors are encoded by about twelve polymorphic genes and are expressed on NK cells and memory $\mathrm{T}$ lymphocytes. The binding to one type of KIR receptor is sufficient to prevent activation of NK cells, whereas it usually takes several different activating signals to induce degranulation and death of the target cell. The CD94/NKG2A receptor, conserved in rodents and primates, is expressed on most NK cells and a subset of CD8+ memory T cells. ${ }^{55}$ CD94 has no cytoplasmic signalization domain while the receptor NKG2A contains two ITIM. ${ }^{56} \mathrm{KIR}$, but also murine Ly49 receptors, bind directly to MHC-I molecules, whereas the CD94/NKG2A receptor binds to a peptide derived from

Table I Main receptors on NK cells involved in anti-tumor immune response

\begin{tabular}{|c|c|c|c|c|}
\hline Function & Receptors & Ligands & Species & Ref \\
\hline \multirow[t]{4}{*}{ Inhibition } & $\mathrm{KIR}$ & HLA-A,B,C allotypes & $\mathrm{H}$ & 42,43 \\
\hline & (long cytoplasmic tail) & & & \\
\hline & Ly49A/C & MHC class I & M & 44,45 \\
\hline & CD94-NKG2A & MHC-E & $\mathrm{H}, \mathrm{M}$ & 48,50 \\
\hline \multirow[t]{7}{*}{ Activation } & CDI6 & $\lg G$ & $\mathrm{H}, \mathrm{M}$ & \\
\hline & & HPV & $\mathrm{H}$ & 61 \\
\hline & NKG2D & MICA/B-RAET & $\mathrm{H}$ & \\
\hline & & RAET-H60 & M & \\
\hline & NKp30 & B7-H6, Heparan sulfate & $\mathrm{H}$ & $75-78$ \\
\hline & NKp44 & Heparan sulfate & $\mathrm{H}$ & 76 \\
\hline & NKp46 & Heparan sulfate, unknown tumor ligands & $\mathrm{H}, \mathrm{M}$ & $75,76,121$ \\
\hline
\end{tabular}

Abbreviations: HLA, human leucocyte antigen; H, Human; Ig, immunoglobulin; M, mouse; MHC, major histocompatibility complex; MICA/B, major histocompatibility complex class I-related; RAET, retinoic acid early transcript. 
the signal sequence of MHC-I. ${ }^{50,54}$ All inhibitory receptors are found by overlapping NK cell subpopulations since each cell expresses only a few types of inhibitory receptors. Consequently, NK cells have many complex combinations of MHC-I repertoire randomly distributed on the cells. The only rule that seems to be established is that all NK cells have at least one inhibitory receptor specific for MHC-I molecule to avoid autoreactivity.

\section{NK cell-activating receptors}

In addition to inhibitory receptors, NK cells express a wide range of activating receptors. Their biological role is not yet fully known because all their ligands have not been identified. The main activating receptors involved in tumor lysis are CD16, NKG2D receptor, and the natural cytotoxicity receptors (NCR) $)^{57-60}$ (Table 1).

The activating receptors have no ITIM in their cytoplasmic domains. Instead, they have charged residues in their transmembrane domains, which are necessary for the association with adapter proteins. These proteins have short extracellular domains and, therefore, do not participate in ligand binding. The intracellular domains of these adapter proteins have docking sites for signaling molecules that play a role downstream of the stimulation. Most of the adapter proteins (FceR $\gamma \mathrm{I}, \mathrm{CD} 3 \zeta$, DAP12, and DAP10) contain immunoreceptor tyrosine-based activation motif in their cytoplasmic domains, which enable them to associate with ZAP70 and/or proteins of syk kinases family. ${ }^{61,62}$

CD16 is a low-affinity receptor for the Fc portion of immunoglobulin (FcyRIII). This receptor with a transmembrane domain (FcyRIIIa) is found on the surface of NK cells but also on some DC, T lymphocytes, monocytes, and macrophages, and a glycosylphosphatidylinositol-linked receptor (FcyRIIIb) is expressed on neutrophils. ${ }^{63}$ When IgG molecules recognize specific antigens on a tumor cell, NK cells, via CD16, are able to bind tumor cell coated with antibodies and induce tumor cell death. This reaction called antibody-dependent cell-mediated cytotoxicity is a dominant component of antibody based immunotherapy against tumors. ${ }^{64}$ Recently, CD16 has been implicated in the recognition of human papillomavirus by NK cells in uterine preneoplastic lesions. ${ }^{65}$

NKG2D, unlike the other NKG2 receptors, does not have an ITIM sequence and is not associated with CD94. ${ }^{66}$ It is expressed on most NK cells but also on $\gamma \delta$ and CD8+ $\mathrm{T}$ cells. It is associated with the adapter molecule DAP10 in humans, and DAP10 and DAP12 in mice. ${ }^{67,68}$ Binding of NKG2D ligands, such as MICA or MICB, leads to an increase in proliferation, cytotoxicity, and production of cytokines and chemokines (IFN- $\gamma$, GM-CSF, TNF- $\alpha$ ). ${ }^{69}$ Expression of NKG2D ligands is observed on many tumor cell lines and tumor tissues. ${ }^{70,71}$

More specifically expressed on NK cells, the principal NCR are NKp46, NKp44, and NKp30. ${ }^{59,72,73}$ Molecular cloning of NCR confirmed that they were structurally distinct although they belong to the same immunoglobulin superfamily. ${ }^{74} \mathrm{NKp} 46$ (human and mice) and NKp30 (human) are expressed on both resting and activated NK cells, while the NKp44 receptor is only present on IL-2-activated human NK cells and a minor subset of $\gamma \delta$ T cells. ${ }^{72}$ The density of NCR on the cell surface varies with individuals and there is a direct correlation between NCR expression on human NK cells and their capacity to kill tumor cells. ${ }^{75} \mathrm{NKp} 46$, the first identified NCR, is a $46 \mathrm{kDa}$ glycoprotein with a transmembrane domain that interacts with the adapter molecule CD3 $\zeta .{ }^{59,76}$ The activation of NKp46 leads to mobilization of calcium in the development of cytolytic activity and cytokine production. ${ }^{59}$ Monoclonal antibodies against NKp46 block the lysis of a wide range of tumor cells showing that this receptor plays a major role in NK cell cytotoxicity. ${ }^{77}$ This function of NKp46 is negatively regulated by the interaction between inhibitory receptors and MHC-I. NKp44 is a $44 \mathrm{kDa}$ glycoprotein whose expression is inducible by IL-2, suggesting that it could contribute to the increased efficiency of activated NK cells to lyse tumor cells. ${ }^{72}$ NKp44 acts in association with the immunoreceptor tyrosine-based activation motif on the adapter molecule DAP12. The blocking of NKp44 by monoclonal antibodies induces a partial inhibition of the cytolytic activity against some tumor cells and this inhibition is strongly enhanced by the addition of antibodies blocking NKp46. ${ }^{78} \mathrm{NKp} 30$ is a glycoprotein of $30 \mathrm{kDa}$ that associates with the adapter molecules $\mathrm{CD} 3 \zeta$ and FceR $\gamma \mathrm{I} .^{73}$ Its expression at the cell surface is correlated with NKp46. In addition, NKp30 cooperates with NKp46 and NKp44 to induce NK cell cytotoxicity against a variety of target cells. ${ }^{73}$ NKp46, NKp44, and NKp30 bind to heparan sulfates on the surface of tumor cells. ${ }^{79,80}$ In addition, NKp30 is involved in the lysis of tumor cells by binding to factor BAT3 (HLA-B associated transcript (3) or to B7-H6 present on their surface..$^{81,82}$

\section{Role of NK cells in immune response against tumor growth and metastasis}

In vivo and in vitro studies have shown that NK cells can eliminate tumor cells. ${ }^{83}$ In mice, tumor rejection is dependent upon the presence or absence of NK cell receptor ligands on 
the tumor. Especially the lack of MHC-I expression, overexpression of NKG2D ligands (H60, Rae1 $\beta$, Rae1 $\delta$, Rae1 $\gamma$, Mult-1), or costimulatory signals makes the tumor more susceptible to lysis by NK cells. ${ }^{84}$ Moreover, engagement of NCR complements NKG2D pathway in the killing of tumor cells by NK cells. ${ }^{85}$ Little is known about the mechanism of NK cell migration in tumor, but selectins seem to play a role in this recruitment. ${ }^{86}$ However, Smyth et $\mathrm{al}^{25,87}$ showed that mice deficient in NK cells are more susceptible to methylcholanthreneinduced sarcomas, demonstrating that NK cells play a role in tumor immunosurveillance. NK cells also protect against the growth of B cell lymphomas in mice lacking perforin and $\beta 2$ microglobulin. ${ }^{88}$ Moreover, NK cells participate to immune response against metastasis; in an immunotherapy protocol using synthetic oligodeoxynucleotides containing $\mathrm{CpG}$ motifs, NK cells prevent pulmonary metastasis and peritoneal dissemination. ${ }^{89}$ In a mouse model, NK cells inhibit pulmonary metastasis formation after IFN- $\gamma$ treatment. ${ }^{90}$

Also, in humans, there is evidence that NK cells play a role in the tumor immunosurveillance. An 11-year follow-up survey has shown that a low NK cell activity is associated with an increased cancer risk. ${ }^{91}$ This was confirmed in several human malignancies. For example, a decrease of NK cell activity is observed in patients with hereditary colorectal adenocarcinoma ${ }^{92,93}$ and melanoma patients with metastatic disease have an impaired perforin-dependent NK cell cytotoxic mechanism. ${ }^{94}$ Tumor growth can disturb the functional maturation of NK cells by interrupting the IL-15 signaling pathway, ${ }^{95}$ but further studies are necessary to better understand the immunologic basis of NK cell defects in tumor.

As already mentioned, NK cells collaborate with antigenpresenting cells to amplify the immune response. ${ }^{96}$ This collaboration can help to induce a T cell-mediated antitumor immunity. ${ }^{97}$ After the implantation of MHC-I low tumor cells in mice, the release of IFN- $\gamma$ by NK cells stimulate the maturation of DC to a IL-12-producing DC1 phenotype that promote a strong and protective antitumor CD8+ T cell response..$^{42,98}$

\section{Implications for tumor management}

The observation that IL-2 increased in vitro the cytotoxic activity of NK cells against tumor cells ${ }^{99}$ has been conducted to perform clinical trials with adoptive transfer of high doses of this cytokine in patients with metastatic melanoma or renal cell carcinoma. ${ }^{100,101}$ Due to systemic toxicity of IL-2 and to the fact that IL-2 preferentially drives expansion of regulatory $T$ cells, which can inhibit antitumor immunity, other cytokines, such as IL-15, were tested in nonhuman primates. IL-15 shares similar properties with IL-2 and Berger et $\mathrm{al}^{102}$ showed that intermittent administration of IL-15 should be considered in clinical studies. Also other cytokines, such as IL-12 and IL-18, synergistically enhance NK cytotoxicity against tumor targets and IFN- $\gamma$ production by NK cells. ${ }^{103,104}$

Tumor-targeted monoclonal antibodies can induce NK cell antibody-dependent cell-mediated cytotoxicity and the rapid degranulation of NK cells results in tumor cell destruction. ${ }^{105}$ The clinical efficacy of monoclonal antibodies directed against CD20 (rituximab), Her2/neu (trastuzumab), epidermal growth factor receptor (cetuximab), or disialoganglioside (GD2) is, at least partially, due to NK antibodydependent cell-mediated cytotoxicity. ${ }^{106-109}$ Moreover, in a Phase I trial, coadministration of IL-12 with trastuzumab enhances the antitumor response induced by the antibody. ${ }^{110}$

Besides the development of protocols to stimulate NK cell activity, inhibitory receptors on NK cells could be the target for antitumor therapy. Blocking Ly49 inhibitory receptors enhanced antitumor activity in vitro and in vivo ${ }^{111}$ and in human, antibodies blocking KIR are currently tested in a Phase II clinical trial. ${ }^{112} \mathrm{NK}$ allogeneic recognition via their KIR repertoire has a major role in reducing the risk of relapse by inducing a graft versus leukemia effect after allogeneic hematopoietic stem cell transplantation. ${ }^{113}$

NK cells seem important in tumor vaccination with DC, since clinical responses are correlated with superior levels of activated NK cells in responders. ${ }^{114}$ In a Phase I clinical trial with melanoma patients, DC derived-exosomes enhanced NKG2D-dependent function of NK cells in half of the patients. ${ }^{115}$ Indirectly, immunotherapy protocols targeting an oncogenic viral protein ${ }^{116}$ or the recruitment of antigenpresenting cells ${ }^{117}$ boost NK cell response. Even some chemotherapeutic agents could inhibit secretion of inhibitory soluble NKG2D ligands. ${ }^{118}$ A NK cell treatment combined with radiation therapy has been proposed, since radiation increases NKactivating ligand (eg, NKG2DL) expression via DNA damage response. ${ }^{119}$ Figure 4 summarizes the different mechanisms implicated into NK cell response against tumor cells.

\section{Role of NK cells in autoimmunity}

NK cells are viewed as effector cells whose rapid killing of transformed or infected cells provides a first-line of defense prior to the initiation of an adaptive immune response against tumor or infection. However, studies on NK cells suggest a broad role in immunity including the potential to function as regulatory cells. While NK cells can assist in DC maturation and $\mathrm{T}$ cell polarization, increasing evidence indicates that NK cells 
can also prevent and limit adaptive autoimmune responses. ${ }^{120}$ Autoimmune diseases are a multistep process caused by inappropriate activation of cells of the adaptive immune system ( $\mathrm{T}$ and B cells) which results in cell-specific, organ-specific, or systemic tissue damage. ${ }^{121}$ Autoimmunity has been linked to cancer, for example, patients with scleroderma have an increased risk to develop a tumor. ${ }^{122}$ Moreover autoimmunity is associated with immunotherapy of cancer. ${ }^{123}$

Several studies suggested that NK cells play a role at the different stages of the autoimmune response. ${ }^{124} \mathrm{NK}$ cells can either augment or ameliorate autoimmune diseases. ${ }^{125,126}$ A reduction of circulating NK cells has been shown in diverse autoimmune diseases, which contributed to an impaired NK activity. ${ }^{127,128}$ The modulation in the number of circulating NK cells seems to be a primary event instead of an active inflammation/drug administration consequence during autoimmune processes. However, some biotherapies are linked with changes of circulating NK cells compartment. Daclizumab (anti-IL-2R $\alpha$ ) treatment in multiple sclerosis ${ }^{129}$ or in uveitis ${ }^{130}$ pathogenesis is associated with an increase in the number of CD56 $6^{\text {bright }} \mathrm{NK}$ cells. This augmentation of CD56 $6^{\text {bright }} \mathrm{NK}$ cells is correlated with the suppression of the disease activity. ${ }^{129} \mathrm{NK}$ cells can also promote autoimmune diseases, ie, autoimmune diabetes is prevented in nonobese-diabetic mice by blocking the activating NK cell receptor NKG2D. ${ }^{131}$ In humans, the predisposition to rheumatoid arthritis, ${ }^{132}$ psoriatic arthritis, ${ }^{133}$ scleroderma, ${ }^{134}$ and psoriasis vulgaris ${ }^{135}$ is linked to the expression of certain KIR and HLA alleles, but the precise role of NK cells in these diseases is still under investigation.

\section{Conclusion}

NK cells could be very efficient killers of tumor cells and could help to induce an optimal adaptive immune response against cancer. A better knowledge in the basic biology of NK cells is a key to develop strategies to manipulate NK cells for therapeutic purposes.

\section{Acknowledgments}

IL and VMR are supported by a Télévie grant from the Belgian National Fund for Scientific Research (FNRS) and $\mathrm{NJ}$ is a research associate of the FNRS.

\section{References}

1. Kiessling R, Klein E, Wigzell H. "Natural" killer cells in the mouse. I. Cytotoxic cells with specificity for mouse Moloney leukemia cells. Specificity and distribution according to genotype. Eur J Immunol. 1975;5(2):112-117.

2. Biron CA, van den Elsen P, Tutt MM, Medveczky P, Kumar V, Terhorst C. Murine natural killer cells stimulated in vivo do not express the $\mathrm{T}$ cell receptor alpha, beta, gamma, T3 delta, or T3 epsilon genes. J Immunol. 1987;139(5):1704-1710.
3. Di Santo JP. Natural killer cell developmental pathways: a question of balance. Annu Rev Immunol. 2006;24:257-286.

4. Kärre K, Ljunggren HG, Piontek G, Kiessling R. Selective rejection of $\mathrm{H}-2$-deficient lymphoma variants suggests alternative immune defence strategy. Nature. 1986;319(6055):675-678.

5. Lanier LL. Natural killer cells: from no receptors to too many. Immunity. 1997;6(4):371-378.

6. Raulet DH, Vance RE, McMahon CW. Regulation of the natural killer cell receptor repertoire. Annu Rev Immunol. 2001;19:291-330.

7. Lanier LL. Missing self, NK cells, and the white album. J Immunol. 2005;174(11):6565.

8. Caligiuri MA. Human natural killer cells. Blood. 2008;112(3): 461-469.

9. Vivier E, Tomasello E, Baratin M, Walzer T, Ugolini S. Functions of natural killer cells. Nat Immunol. 2008;9(5):503-510.

10. Wu J, Lanier LL. Natural killer cells and cancer. Adv Cancer Res. 2003;90:127-156.

11. King A, Burrows T, Loke YW. Human uterine natural killer cells. Nat Immun. 1996;15(1):41-52.

12. Luo D, Vermijlen D, Vanderkerken $\mathrm{K}$, et al. Involvement of LFA-1 in hepatic NK cell (pit cell)-mediated cytolysis and apoptosis of colon carcinoma cells. J Hepatol. 1999;31(1):110-116.

13. Robertson MJ, Ritz J. Biology and clinical relevance of human natural killer cells. Blood. 1990;76(12):2421-2438.

14. Trinchieri G. Biology of natural killer cells. Adv Immunol. 1989; 47:187-376.

15. Nagler A, Lanier LL, Cwirla S, Phillips JH. Comparative studies of human FcRIII-positive and negative natural killer cells. J Immunol. 1989;143(10):3183-3191.

16. Cooper MA, Fehniger TA, Turner SC, et al. Human natural killer cells: a unique innate immunoregulatory role for the CD56(bright) subset. Blood. 2001;97(10):3146-3151.

17. Hayakawa Y, Smyth MJ. CD27 dissects mature NK cells into two subsets with distinct responsiveness and migratory capacity. J Immunol. 2006;176(3):1517-1524.

18. Walzer T, Blery M, Chaix J, et al. Identification, activation, and selective in vivo ablation of mouse NK cells via NKp46. Proc Natl Acad Sci U S A. 2007;104(9):3384-3389.

19. Gong JH, Maki G, Klingemann HG. Characterization of a human cell line (NK-92) with phenotypical and functional characteristics of activated natural killer cells. Leukemia. 1994;8(4):652-658.

20. Cheng M, Ma J, Chen Y, et al. Establishment, characterization and successful adaptive therapy against human tumors of NKG Cell, a new human NK cell line. Cell Transplant. June 7, 2011. [Epub ahead of print.]

21. Ortaldo JR, Oldham RK, Cannon GC, Herberman RB. Specificity of natural cytotoxic reactivity of normal human lymphocytes against a myeloid leukemia cell line. J Natl Cancer Inst. 1977;59(1):77-82.

22. Riccardi C, Santoni A, Barlozzari T, Puccetti P, Herberman RB. In vivo natural reactivity of mice against tumor cells. Int $J$ Cancer. 1980;25(4):475-486.

23. Kim S, Iizuka K, Aguila HL, Weissman IL, Yokoyama WM. In vivo natural killer cell activities revealed by natural killer cell-deficient mice. Proc Natl Acad Sci U S A. 2000;97(6):2731-2736.

24. Smyth MJ, Cretney E, Takeda K, et al. Tumor necrosis factor-related apoptosis-inducing ligand (TRAIL) contributes to interferon gammadependent natural killer cell protection from tumor metastasis. J Exp Med. 2001;193(6):661-670.

25. Smyth MJ, Crowe NY, Godfrey DI. NK cells and NKT cells collaborate in host protection from methylcholanthrene-induced fibrosarcoma. Int Immunol. 2001;13(4):459-463.

26. Halfteck GG, Elboim M, Gur C, Achdout H, Ghadially H, Mandelboim O. Enhanced in vivo growth of lymphoma tumors in the absence of the NK-activating receptor NKp46/NCR1. J Immunol. 2009; 182(4):2221-2230.

27. Lodoen MB, Lanier LL. Viral modulation of NK cell immunity. Nat Rev Microbiol. 2005;3(1):59-69. 
28. Garrido F, Algarra I. MHC antigens and tumor escape from immune surveillance. Adv Cancer Res. 2001;83:117-158.

29. Hewitt EW. The MHC class I antigen presentation pathway: strategies for viral immune evasion. Immunology. 2003;110(2):163-169.

30. Clement MV, Haddad P, Soulie A, et al. Involvement of granzyme B and perforin gene expression in the lytic potential of human natural killer cells. Res Immunol. 1990;141(6):477-489.

31. Bryceson YT, March ME, Ljunggren HG, Long EO. Activation, coactivation, and costimulation of resting human natural killer cells. Immunol Rev. 2006;214:73-91.

32. Kagi D, Ledermann B, Burki K, et al. Cytotoxicity mediated by $\mathrm{T}$ cells and natural killer cells is greatly impaired in perforin-deficient mice. Nature. 1994;369(6475):31-37.

33. Smyth MJ, Thia KY, Street SE, MacGregor D, Godfrey DI, Trapani JA. Perforin-mediated cytotoxicity is critical for surveillance of spontaneous lymphoma. J Exp Med. 2000;192(5):755-760.

34. Cao X, Cai SF, Fehniger TA, et al. Granzyme B and perforin are important for regulatory $\mathrm{T}$ cell-mediated suppression of tumor clearance. Immunity. 2007;27(4):635-646.

35. Zamai L, Ahmad M, Bennett IM, Azzoni L, Alnemri ES, Perussia B. Natural killer (NK) cell-mediated cytotoxicity: differential use of TRAIL and Fas ligand by immature and mature primary human NK cells. J Exp Med. 1998;188(12):2375-2380.

36. Takeda K, Hayakawa Y, Smyth MJ, et al. Involvement of tumor necrosis factor-related apoptosis-inducing ligand in surveillance of tumor metastasis by liver natural killer cells. Nat Med. 2001;7(1):94-100.

37. Trinchieri G. Natural killer cells wear different hats: effector cells of innate resistance and regulatory cells of adaptive immunity and of hematopoiesis. Semin Immunol. 1995;7(2):83-88.

38. Street SE, Cretney E, Smyth MJ. Perforin and interferon-gamma activities independently control tumor initiation, growth, and metastasis. Blood. 2001;97(1):192-197.

39. Angiolillo AL, Sgadari C, Taub DD, et al. Human interferon-inducible protein 10 is a potent inhibitor of angiogenesis in vivo. $J$ Exp Med. 1995;182(1):155-162.

40. Biron CA, Nguyen KB, Pien GC, Cousens LP, Salazar-Mather TP. Natural killer cells in antiviral defense: function and regulation by innate cytokines. Аппи Rev Immunol. 1999;17:189-220.

41. Snijders A, Kalinski P, Hilkens CM, Kapsenberg ML. High-level IL-12 production by human dendritic cells requires two signals. Int Immunol. 1998;10(11):1593-1598.

42. Adam C, King S, Allgeier T, et al. DC-NK cell cross talk as a novel CD4+ T-cell-independent pathway for antitumor CTL induction. Blood. 2005;106(1):338-344.

43. Jacobs N, Boniver J, Hubert P, Delvenne P. Dendritic cells: more than just adaptive immunity inducers? Curr Immunol Rev. 2007;3:17-22.

44. Ljunggren HG, Kärre K. Host resistance directed selectively against H-2-deficient lymphoma variants. Analysis of the mechanism. $J$ Exp Med. 1985;162(6):1745-1759.

45. Franksson L, George E, Powis S, Butcher G, Howard J, Kärre K. Tumorigenicity conferred to lymphoma mutant by major histocompatibility complex-encoded transporter gene. J Exp Med. 1993;177(1): 201-205.

46. Ljunggren HG, Sturmhofel K, Wolpert E, Hammerling GJ, Kärre K. Transfection of beta 2-microglobulin restores IFN-mediated protection from natural killer cell lysis in YAC-1 lymphoma variants. J Immunol. 1990;145(1):380-386.

47. Wagtmann N, Rajagopalan S, Winter CC, Peruzzi M, Long EO. Killer cell inhibitory receptors specific for HLA-C and HLA-B identified by direct binding and by functional transfer. Immunity. 1995;3(6):801-809.

48. Jamil KM, Khakoo SI. KIR/HLA interactions and pathogen immunity. J Biomed Biotechnol. 2011;2011:298348.

49. Yokoyama WM, Jacobs LB, Kanagawa O, Shevach EM, Cohen DI. A murine $\mathrm{T}$ lymphocyte antigen belongs to a supergene family of type II integral membrane proteins. J Immunol. 1989;143(4): 1379-1386.
50. Orr MT, Lanier LL. Inhibitory Ly49 receptors on mouse natural killer cells. Curr Top Microbiol Immunol. 2011;350:67-87.

51. Carretero M, Cantoni C, Bellon T, et al. The CD94 and NKG2-A C-type lectins covalently assemble to form a natural killer cell inhibitory receptor for HLA class I molecules. Eur J Immunol. 1997;27(2):563-567.

52. Houchins JP, Yabe T, McSherry C, Bach FH. DNA sequence analysis of NKG2, a family of related cDNA clones encoding type II integral membrane proteins on human natural killer cells. J Exp Med. 1991;173(4):1017-1020.

53. Petrie EJ, Clements CS, Lin J, et al. CD94-NKG2A recognition of human leukocyte antigen (HLA)-E bound to an HLA class I leader sequence. $J$ Exp Med. 2008;205(3):725-735.

54. Le Drean E, Vely F, Olcese L, et al. Inhibition of antigen-induced $T$ cell response and antibody-induced NK cell cytotoxicity by NKG2 A: association of NKG2 A with SHP-1 and SHP-2 protein-tyrosine phosphatases. Eur J Immunol. 1998;28(1):264-276.

55. Masilamani M, Nguyen C, Kabat J, Borrego F, Coligan J. CD94/ NKG2A inhibits NK cell activation by disrupting the actin network at the immunological synapse. J Immunol. 2006;177(6):3590-3596.

56. Carretero M, Palmieri G, Llano M, et al. Specific engagement of the CD94/NKG2-A killer inhibitory receptor by the HLA-E class Ib molecule induces SHP-1 phosphatase recruitment to tyrosine-phosphorylated NKG2-A: evidence for receptor function in heterologous transfectants. Eur J Immunol. 1998;28(4):1280-1291.

57. Bauer S, Groh V, Wu J, et al. Activation of NK cells and T cells by NKG2D, a receptor for stress-inducible MICA. Science. 1999;285(5428): 727-729.

58. Biassoni R. Natural killer cell receptors. Adv Exp Med Biol. 2008; 640:35-52.

59. Sivori S, Vitale M, Morelli L, et al. p46, a novel natural killer cellspecific surface molecule that mediates cell activation. J Exp Med. 1997;186(7):1129-1136.

60. Bryceson YT, March ME, Barber DF, Ljunggren HG, Long EO. Cytolytic granule polarization and degranulation controlled by different receptors in resting NK cells. $J$ Exp Med. 2005;202(7):1001-1012.

61. Lanier LL, Corliss BC, Wu J, Leong C, Phillips JH. Immunoreceptor DAP12 bearing a tyrosine-based activation motif is involved in activating NK cells. Nature. 1998;391(6668):703-707.

62. Olcese L, Cambiaggi A, Semenzato G, Bottino C, Moretta A, Vivier E. Human killer cell activatory receptors for MHC class I molecules are included in a multimeric complex expressed by natural killer cells. J Immunol. 1997;158(11):5083-5086.

63. Moldovan I, Galon J, Maridonneau-Parini I, et al. Regulation of production of soluble Fc gamma receptors type III in normal and pathological conditions. Immunol Lett. 1999;68(1):125-134.

64. Nimmerjahn F, Ravetch JV. Antibodies, Fc receptors and cancer. Curr Opin Immunol. 2007;19(2):239-245.

65. Renoux V, Bisig B, Langers I, et al. Human papillomavirus entry into NK cells requires CD16 expression and triggers cytotoxic activity and cytokine secretion. Eur J Immunol. 2011;44(11):3240-3252.

66. Ho EL, Heusel JW, Brown MG, Matsumoto K, Scalzo AA, Yokoyama WM. Murine Nkg2d and Cd94 are clustered within the natural killer complex and are expressed independently in natural killer cells. Proc Natl Acad Sci U S A. 1998;95(11):6320-6325.

67. Champsaur M, Lanier LL. Effect of NKG2D ligand expression on host immune responses. Immunol Rev. 2010;235(1):267-285.

68. Rosen DB, Araki M, Hamerman JA, Chen T, Yamamura T, Lanier LL. A Structural basis for the association of DAP12 with mouse, but not human, NKG2D. J Immunol. 2004;173(4):2470-2478.

69. Sutherland CL, Chalupny NJ, Schooley K, VandenBos T, Kubin M, Cosman D. UL16-binding proteins, novel MHC class I-related proteins, bind to NKG2D and activate multiple signaling pathways in primary NK cells. J Immunol. 2002;168(2):671-679.

70. Groh V, Bahram S, Bauer S, Herman A, Beauchamp M, Spies T. Cell stress-regulated human major histocompatibility complex class I gene expressed in gastrointestinal epithelium. Proc Natl Acad Sci U S A. 1996;93(22):12445-12450. 
71. Cerwenka A. New twist on the regulation of NKG2D ligand expression. J Exp Med. 2009;206(2):265-268.

72. Cantoni C, Bottino C, Vitale M, et al. NKp44, a triggering receptor involved in tumor cell lysis by activated human natural killer cells, is a novel member of the immunoglobulin superfamily. $J$ Exp Med. 1999;189(5):787-796.

73. Pende D, Parolini S, Pessino A, et al. Identification and molecular characterization of $\mathrm{NKp} 30$, a novel triggering receptor involved in natural cytotoxicity mediated by human natural killer cells. $J$ Exp Med. 1999;190(10):1505-1516.

74. Bottino C, Biassoni R, Millo R, Moretta L, Moretta A. The human natural cytotoxicity receptors (NCR) that induce HLA class I-independent NK cell triggering. Hum Immunol. 2000;61(1):1-6.

75. Costello RT, Sivori S, Marcenaro E, et al. Defective expression and function of natural killer cell-triggering receptors in patients with acute myeloid leukemia. Blood. 2002;99(10):3661-3667.

76. Pessino A, Sivori S, Bottino C, et al. Molecular cloning of NKp46: a novel member of the immunoglobulin superfamily involved in triggering of natural cytotoxicity. J Exp Med. 1998;188(5):953-960.

77. Sivori S, Pende D, Bottino C, et al. NKp46 is the major triggering receptor involved in the natural cytotoxicity of fresh or cultured human NK cells. Correlation between surface density of NKp46 and natural cytotoxicity against autologous, allogeneic or xenogeneic target cells Eur J Immunol. 1999;29(5):1656-1666.

78. Vitale M, Bottino C, Sivori S, et al. NKp44, a novel triggering surface molecule specifically expressed by activated natural killer cells, is involved in non-major histocompatibility complex-restricted tumor cell lysis. J Exp Med. 1998;187(12):2065-2072.

79. Bloushtain N, Qimron U, Bar-Ilan A, et al. Membrane-associated heparan sulfate proteoglycans are involved in the recognition of cellular targets by NKp30 and NKp46. J Immunol. 2004;173(4): 2392-2401.

80. Hecht ML, Rosental B, Horlacher T, et al. Natural cytotoxicity receptors NKp30, NKp44 and NKp46 bind to different heparan sulfate/heparin sequences. J Proteome Res. 2009;8(2):712-720.

81. Pogge von Strandmann E, Simhadri VR, von Tresckow B, et al. Human leukocyte antigen-B-associated transcript 3 is released from tumor cells and engages the NKp30 receptor on natural killer cells. Immunity. 2007;27(6):965-974.

82. Brandt CS, Baratin M, Yi EC, et al. The B7 family member B7-H6 is a tumor cell ligand for the activating natural killer cell receptor NKp30 in humans. J Exp Med. 2009;206(7):1495-1503.

83. Stagg J, Smyth MJ. NK cell-based cancer immunotherapy. Drug News Perspect. 2007;20(3):155-163.

84. Diefenbach A, Jensen ER, Jamieson AM, Raulet DH. Rae1 and H60 ligands of the NKG2D receptor stimulate tumour immunity. Nature. 2001;413(6852):165-171.

85. Pende D, Cantoni C, Rivera P, et al. Role of NKG2D in tumor cell lysis mediated by human NK cells: cooperation with natural cytotoxicity receptors and capability of recognizing tumors of nonepithelial origin. Eur J Immunol. 2001;31(4):1076-1086.

86. Sobolev O, Stern P, Lacy-Hulbert A, Hynes RO. Natural killer cells require selectins for suppression of subcutaneous tumors. Cancer Res. 2009;69(6):2531-2539.

87. Smyth MJ, Swann J, Cretney E, Zerafa N, Yokoyama WM, Hayakawa Y. NKG2D function protects the host from tumor initiation. $J$ Exp Med. 2005;202(5):583-588.

88. Street SE, Hayakawa Y, Zhan Y, et al. Innate immune surveillance of spontaneous B cell lymphomas by natural killer cells and gammadelta T cells. J Exp Med. 2004;199(6):879-884.

89. Zhou S, Kawakami S, Higuchi Y, Yamashita F, Hashida M. The involvement of NK cell activation following intranasal administration of $\mathrm{CpG}$ DNA lipoplex in the prevention of pulmonary metastasis and peritoneal dissemination in mice. Clin Exp Metastasis. 2012;29(1):63-70.

90. Ksienzyk A, Neumann B, Nandakumar R, et al. IRF-1 expression is essential for natural killer cells to suppress metastasis. Cancer Res. 2011;71(20):6410-6418.
91. Imai K, Matsuyama S, Miyake S, Suga K, Nakachi K. Natural cytotoxic activity of peripheral-blood lymphocytes and cancer incidence: an 11-year follow-up study of a general population. Lancet. 2000;356(9244):1795-1799.

92. Warren RP, Stembridge AM, Gardner EJ. Deficient immune function of peripheral blood mononuclear cells from patients with Gardner syndrome. Clin Exp Immunol. 1985;60(3):525-531.

93. Markowitz JF, Aiges HW, Cunningham-Rundles S, et al. Cancer family syndrome: marker studies. Gastroenterology. 1986;91(3):581-589.

94. Jović V, Konjević G, Radulović S, Jelić S, Spuzić I. Impaired perforin-dependent NK cell cytotoxicity and proliferative activity of peripheral blood $\mathrm{T}$ cells is associated with metastatic melanoma. Tumori. 2001;87(5):324-329.

95. Richards JO, Chang X, Blaser BW, Caligiuri MA, Zheng P, Liu Y. Tumor growth impedes natural-killer-cell maturation in the bone marrow. Blood. 2006;108(1):246-252.

96. Reschner A, Hubert P, Delvenne P, Boniver J, Jacobs N. Innate lymphocyte and dendritic cell cross-talk: a key factor in the regulation of the immune response. Clin Exp Immunol. 2008;152(2):219-226.

97. Kelly JM, Darcy PK, Markby JL, et al. Induction of tumor-specific $\mathrm{T}$ cell memory by NK cell-mediated tumor rejection. Nat Immunol. 2002;3(1):83-90.

98. Mocikat R, Braumuller H, Gumy A, et al. Natural killer cells activated by MHC class I(low) targets prime dendritic cells to induce protective CD8 T cell responses. Immunity. 2003;19(4):561-569.

99. Grimm EA, Mazumder A, Zhang HZ, Rosenberg SA. Lymphokineactivated killer cell phenomenon. Lysis of natural killer-resistant fresh solid tumor cells by interleukin 2-activated autologous human peripheral blood lymphocytes. J Exp Med. 1982;155(6):1823-1841.

100. Atkins MB, Lotze MT, Dutcher JP, et al. High-dose recombinant interleukin 2 therapy for patients with metastatic melanoma: analysis of 270 patients treated between 1985 and 1993. J Clin Oncol. 1999;17(7):2105-2116.

101. Sosman JA, Hank JA, Moore KH, et al. Prolonged interleukin-2 (IL-2) treatment can augment immune activation without enhancing antitumor activity in renal cell carcinoma. Cancer Invest. 1991;9(1):35-48.

102. Berger C, Berger M, Hackman RC, et al. Safety and immunologic effects of IL-15 administration in nonhuman primates. Blood. 2009; 114(12):2417-2426.

103. Lauwerys BR, Garot N, Renauld JC, Houssiau FA. Cytokine production and killer activity of NK/T-NK cells derived with IL-2, IL-15, or the combination of IL-12 and IL-18. J Immunol. 2000; 165(4):1847-1853.

104. Golab J, Zagozdzon R, Kozar K, et al. Potentiatied anti-tumor effectiveness of combined therapy with interleukin- 12 and mitoxantrone of L1210 leukemia in vivo. Oncol Rep. 2000;7(1):177-181.

105. Sondel PM, Hank JA. Antibody-directed, effector cell-mediated tumor destruction. Hematol Oncol Clin North Am. 2001;15(4):703-721.

106. Winter MC, Hancock BW. Ten years of rituximab in NHL. Expert Opin Drug Saf. 2009;8(2):223-235.

107. Garnock-Jones KP, Keating GM, Scott LJ. Trastuzumab: a review of its use as adjuvant treatment in human epidermal growth factor receptor 2 (HER2)-positive early breast cancer. Drugs. 2010;70(2): 215-239.

108. Garcia-Foncillas J, Diaz-Rubio E. Progress in metastatic colorectal cancer: growing role of cetuximab to optimize clinical outcome. Clin Transl Oncol. 2010;12(8):533-542.

109. Navid F, Santana VM, Barfield RC. Anti-GD2 antibody therapy for GD2-expressing tumors. Curr Cancer Drug Targets. 2010;10(2): 200-209.

110. Bekaii-Saab TS, Roda JM, Guenterberg KD, et al. A phase I trial of paclitaxel and trastuzumab in combination with interleukin-12 in patients with HER2/neu-expressing malignancies. Mol Cancer Ther. 2009;8(11):2983-2991.

111. Koh CY, Blazar BR, George T, et al. Augmentation of antitumor effects by NK cell inhibitory receptor blockade in vitro and in vivo. Blood. 2001;97(10):3132-3137. 
112. Alici E. IPH-2101, a fully human anti-NK-cell inhibitory receptor $\mathrm{mAb}$ for the potential treatment of hematological cancers. Curr Opin Mol Ther. 2010;12(6):724-733.

113. Pegram HJ, Ritchie DS, Smyth MJ, et al. Alloreactive natural killer cells in hematopoietic stem cell transplantation. Leuk Res. 2011;35(1):14-21.

114. Van Tendeloo VF, Van de Velde A, Van Driessche A, et al. Induction of complete and molecular remissions in acute myeloid leukemia by Wilms' tumor 1 antigen-targeted dendritic cell vaccination. Proc Natl Acad Sci U S A. 2010;107(31):13824-13829.

115. Viaud S, Thery C, Ploix S, et al. Dendritic cell-derived exosomes for cancer immunotherapy: what's next? Cancer Res. 2010;70(4): 1281-1285.

116. Hallez S, Simon P, Maudoux F, et al. Phase I/II immunogenicity of a Human Papillomavirus (HPV) type 16 E7 protein-based vaccine in women with oncogenic HPV-positive cervical intraepithelial neoplasia. Cancer Immunol Immunother. 2004;53(7):642-650.

117. Hubert P, Doyen J, Capelle X, et al. Local applications of GM-CSF induce the recruitment of immune cells in cervical low-grade squamous intraepithelial lesions. Am J Reprod Immunol. 2010;64:126-136.

118. Andresen L, Skovbakke S, Persson G, et al. 2-Deoxy d-glucose prevents cell surface expression of $n k g 2 d$ ligands through inhibition of n-linked glycosylation. J Immunol. 2012;188(4):1847-1855.

119. Gasser S, Orsulic S, Brown EJ, Raulet DH. The DNA damage pathway regulates innate immune system ligands of the NKG2D receptor. Nature. 2005;436(7054):1186-1190.

120. Lunemann A, Lunemann JD, Munz C. Regulatory NK-cell functions in inflammation and autoimmunity. Mol Med. 2009; 15(9-10):352-358.

121. Shi FD, Ljunggren HG, Sarvetnick N. Innate immunity and autoimmunity: from self-protection to self-destruction. Trends Immunol. 2001;22(2):97-101.

122. Shah AA, Rosen A. Cancer and systemic sclerosis: novel insights into pathogenesis and clinical implications. Curr Opin Rheumatol. 2011;23(6):530-535.

123. Amos SM, Duong CP, Westwood JA, et al. Autoimmunity associated with immunotherapy of cancer. Blood. 2011;118(3):499-509.

124. Shi FD, Zhou Q. Natural killer cells as indispensable players and therapeutic targets in autoimmunity. Autoimmunity. 2011;44(1):3-10.
125. Shi FD, Wang HB, Li H, et al. Natural killer cells determine the outcome of B cell-mediated autoimmunity. Nat Immunol. 2000;1(3):245-251.

126. Kitaichi N, Kotake S, Morohashi T, Onoe K, Ohno S, Taylor AW. Diminution of experimental autoimmune uveoretinitis (EAU) in mice depleted of NK cells. J Leukoc Biol. 2002;72(6):1117-1121.

127. Erkeller-Yusel F, Hulstaart F, Hannet I, Isenberg D, Lydyard P. Lymphocyte subsets in a large cohort of patients with systemic lupus erythematosus. Lupus. 1993;2(4):227-231.

128. Aramaki T, Ida H, Izumi Y, et al. A significantly impaired natural killer cell activity due to a low activity on a per-cell basis in rheumatoid arthritis. Mod Rheumatol. 2009;19(3):245-252.

129. Bielekova B, Catalfamo M, Reichert-Scrivner S, et al. Regulatory CD56(bright) natural killer cells mediate immunomodulatory effects of IL-2Ralpha-targeted therapy (daclizumab) in multiple sclerosis. Proc Natl Acad Sci U S A. 2006;103(15):5941-5946.

130. Li Z, Lim WK, Mahesh SP, Liu B, Nussenblatt RB. Cutting edge: in vivo blockade of human IL-2 receptor induces expansion of CD56(bright) regulatory NK cells in patients with active uveitis. J Immunol. 2005;174(9):5187-5191.

131. Ogasawara K, Hamerman JA, Hsin H, et al. Impairment of NK cell function by NKG2D modulation in NOD mice. Immunity. 2003;18(1):41-51.

132. Namekawa T, Snyder MR, Yen JH, et al. Killer cell activating receptors function as costimulatory molecules on CD4+CD28null $\mathrm{T}$ cells clonally expanded in rheumatoid arthritis. J Immunol. 2000;165(2):1138-1145.

133. Martin MP, Nelson G, Lee JH, et al. Cutting edge: susceptibility to psoriatic arthritis: influence of activating killer Ig-like receptor genes in the absence of specific HLA-C alleles. J Immunol. 2002;169(6):2818-2822.

134. Momot T, Koch S, Hunzelmann N, et al. Association of killer cell immunoglobulin-like receptors with scleroderma. Arthritis Rheum. 2004;50(5):1561-1565.

135. Suzuki Y, Hamamoto Y, Ogasawara Y, et al. Genetic polymorphisms of killer cell immunoglobulin-like receptors are associated with susceptibility to psoriasis vulgaris. J Invest Dermatol. 2004;122(5):1133-1136.
Biologics: Targets \& Therapy

\section{Publish your work in this journal}

Biologics: Targets \& Therapy is an international, peer-reviewed journal focusing on the patho-physiological rationale for and clinical application of Biologic agents in the management of autoimmune diseases, cancers or other pathologies where a molecular target can be identified. This journal is indexed on PubMed Central, CAS, EMBase, Scopus

\section{Dovepress}

and the Elsevier Bibliographic databases. The manuscript management system is completely online and includes a very quick and fair peerreview system, which is all easy to use. Visit http://www.dovepress. com/testimonials.php to read real quotes from published authors. 